\title{
User Acceptance of SMS-Based eGovernment Services
}

\author{
Tony Dwi Susanto ${ }^{1,2}$ and Robert Goodwin ${ }^{1}$ \\ ${ }^{1}$ CSEM, the Flinders University of South Australia, Adelaide, South Australia \\ ${ }^{2}$ Information Systems Department, ITS, Surabaya, Indonesia \\ \{susa0004, robert.goodwin\}@flinders.edu.au
}

\begin{abstract}
Delivering public services through the SMS channel is becoming popular and has demonstrated its benefits. Some of the initiatives involved big investment. However, citizens' acceptance of the services is still an issue. This paper presents a study on user acceptance of SMS-based e-government services. It assesses the adequacy of four prominent models of technology adoption (TRA, TAM, TPB, and DTPB) to explain intention to use SMS-based egovernment services and proposes a generic model of individual acceptance of SMS-based e-government services. Constructs of the proposed model were derived from a survey on citizens' motivations for using SMS-based egovernment services, theories on individual acceptance of technologies, and user acceptance determinants of SMS and e-government services. Data for validating the models were collected from 589 citizens in three cities in Indonesia. The proposed model may explain why individuals accept or reject SMS-based e-government services and how user acceptance is influenced by the service characteristics.
\end{abstract}

Keywords: SMS, e-government, user acceptance, DTPB, TPB, TAM, TRA.

\section{Introduction}

SMS-based e-government refers to the use of SMS technology for providing information and public services to citizens (G2C), business (G2B), and government employees or other government organizations (G2G). The services are available as notification, pull-based information, communication, and transaction services. Some of them have been integrated with existing Internet-based e-government systems [1].

Currently, benefits of SMS-based e-government are harvested by many local authorities. They include reducing time and cost for public services; introducing a cheaper, easier and faster information-accessing channel; improving transparency, accountability, communication and the relationship between government and citizens; making the services and procedures easier for citizens to use; improving the district political image; increasing citizens participation; and promoting e-Democracy [2, 3].

In light of these benefits, SMS-based e-government is becoming popular and some of the initiatives have involved big investment. The Australian government, for example, allocated \$15 million for setting up a National Emergency Warning System (NEWS) that will send text alerts to the mobile phones of residents threatened by bushfires, disease epidemics, sieges, cyclones, terrorist attacks, locust plagues and heat or smog. 
Despite the important roles of SMS-based e-government and substantial growth in the development of the services, some cases revealed that user acceptance of SMSbased e-government services is still an issue. Lallana [2] and Alampay [4] reported that even though SMS is very popular in the Philippines, some SMS-based egovernment services in the country did not have many users. Similar cases in Denmark and Sweden also suggested that there are factors other than the popularity of SMS and awareness of the services which influence people to use SMS-based egovernment services [5]. The popularity of SMS and awareness of the benefits of SMS-based e-government do not guarantee most citizens will use the services. It is a serious issue, since governments may not obtain the potential benefits of SMS-based e-government and cannot justify the investment in SMS-based e-government systems unless citizens actually use the services. Accordingly, studies on user acceptance of SMS-based e-government services are needed.

This paper is a part of a study investigating factors that may influence individuals to use SMS-based e-government services. It proposes a model of individual acceptance of SMS-based e-government. The model aims to understand why non-adopters reject SMS-based e-government services and what factors would influence them to use the services. From a practical standpoint, this study is interesting not only in explaining why an SMS-based e-government service is unacceptable to a set of users, but also in understanding how to improve user acceptance through the design of the system and the service. This knowledge should be important for government and e-government practitioners to predict user acceptance of a new SMS-based e-government service and to evaluate present SMS-based e-government service

\section{Research Methodology}

To formulate a model of user acceptance of SMS-based e-government services, the current study involved two main activities. The first is to formulate a research model and the second is to empirically compare four prominent models (TRA, TAM, TPB, and DTPB) and the proposed model.

To formulate a research model, this study used both inductive and deductive approaches. For the inductive approach, this study collected empirical data on individuals' motivations for using or not using SMS-based e-government services. A triangulation method combining a web-based survey, a paper questionnaire and a phone-call interview was used to improve the validity of the collected data. For the deductive approach, this study assumed that determinants of adopting SMS-based egovernment services are composed by determinants of adopting SMS and e-government services. Hence, this approach derived the acceptance factors theoretically from prominent models of individual acceptance of technologies and user acceptance of SMS and e-government services found in four research directions' literatures: adoption research, diffusion research, uses and gratifications, and domestication studies. The study extracted the factors to formulate a conceptual model of individual acceptance of SMS-based e-government services.

To validate the proposed model empirically, this study used data from citizens in three cities in Indonesia, structural equation modelling (SEM) and AMOS 18. It empirically compared the adequacy of the four models to explain intention to use SMS-based e-government services, validated the research model and generated a better fit model. 


\section{Formulation of a Research Model}

To identify the adoption factors of SMS-based e-government services, a survey investigating citizens' motivations for using or not using SMS-based e-government services has been conducted over three months (April - June 2010) collecting 159 responses from 25 countries. The majority of the respondents were from Indonesia and India (66.7\%), male, 31-40 years old and included respondents who have Internet access and ones who do not. The survey identified 15 beliefs which may influence individuals to use or to reject an SMS service: perceptions about ease of use, efficiency in time and distance, value for money, responsiveness, relevance of the information, flexibility to access the services, trust in SMS technology, quality and reliability of the content, risk to user privacy, reliability of the system and the mobile network, trust the government and quality of public services, risk to money, availability of the device and infrastructure, compatibility, and self efficacy to use SMS [6].

Further, to compose the factors into a research model, this study reviewed extant technology adoption models and user acceptance of SMS and e-government services. The proposed model focuses on factors determining usage intention since this study aims to discover what factors influence non-adopters to use SMS-based e-government services and usage intention is confirmed as the strongest predictor of actual usage $[7,8,9,10]$. Usage intention has been also confirmed as the strongest predictor of usage behavior of SMS-based services [11].

Among prominent technology adoption models, in order to compose a research model, this study adopted the decomposed theory of planned behaviour (DTPB) for the following reasons. First, the DTPB was developed especially for understanding information technology use [7] and effectively explained individual intentions and behavior in adopting e-government services [12] and mobile services [13]. Second, the acceptance of SMS-based e-government services is not entirely in citizens' control: the condition satisfies core assumption of the DTPB that the presence of constraints including self-efficacy and facilitating conditions (such as the absence of mobile device or lack of skills to use SMS) can inhibit both the intent to use the service and the usage behavior itself. Third, the DTPB incorporates social influence that seems relevant for collaborative systems in the everyday life context like SMSbased e-government [14]. Fourth, the DTPB with its decomposition approach offers two advantages over other prominent models with monolithic belief structures (such as TRA, TAM, and TPB): studies showed that monolithic belief structures, representing a variety of dimensions, are not consistently related to the antecedents of intention [7]; the decomposition approach, on the contrary, can provide a stable set of beliefs which can be applied across various settings overcoming some of the disadvantages in operationalization noted with other traditional intention models [15]. Moreover, due to the elaborate nature of the TPB, the DTPB provides a more complete understanding of usage behaviour relative to parsimonious models such as the TAM and the TPB [7]. The last but not least is the survey conducted by this study 


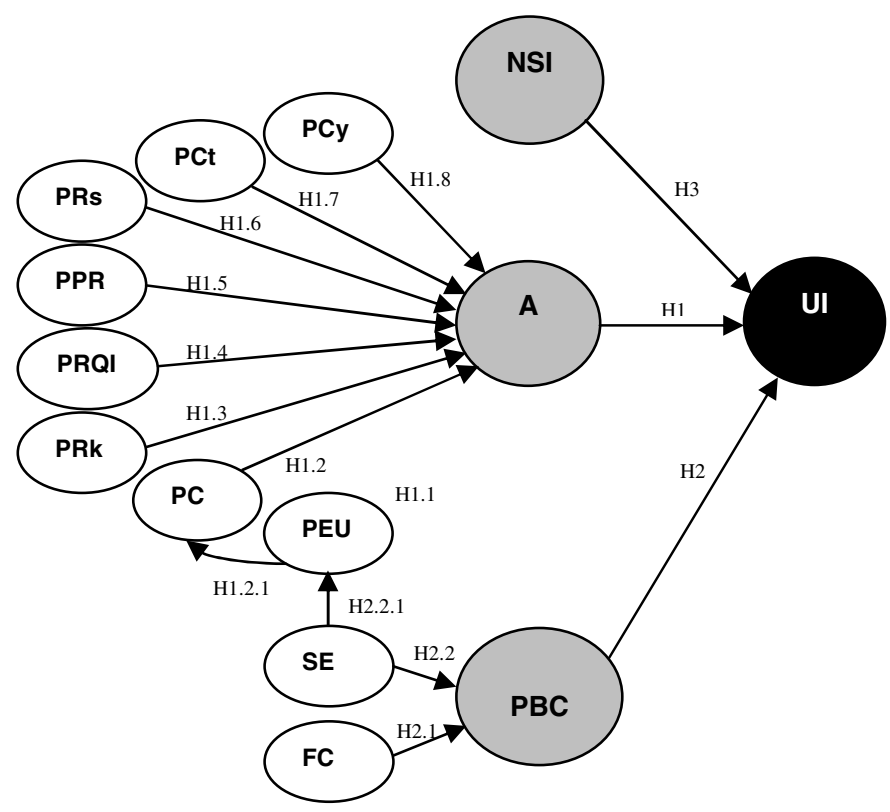

Fig. 1. Research model

also revealed that individuals' motives for using SMS-based e-government services include attitudinal beliefs, social beliefs, and control beliefs as suggested in the DTPB model.

This study hypothesizes that attitude towards using SMS-based e-government services (A), perceived behavioral control (PBC) and normative social influence (NSI) will play a significant role as direct determinants of usage intention of SMSbased e-government services. PBC is composed of two beliefs: facilitating conditions (FC) and self-efficacy (SE); social influences are composed of one belief: normative social influence (NSI); and attitude are composed of eight beliefs: perceived ease of use (PEU), perceived convenience ( $\mathrm{PC})$, perceived reliability and quality of the information (PRQI), perceived cost (PCt), perceived personal relationship (PPR), perceived responsiveness (PRs), perceived risk (PRk), and perceived compatibility (PCy).

Compared to the original DTPB model, this study introduced six attitudinal beliefs specifically for user acceptance of SMS-based e-government services: perceived convenience (PC), perceived reliability and quality of the information (PRQI), perceived cost ( $\mathrm{PCt})$, perceived personal relationship (PPR), perceived responsiveness (PRs), and perceived risk (PRk). Instead of using general term of perceived usefulness, it proposed perceived convenience.

Figure 1, Table 1, and Table 2 present the research model, definitions of the constructs, and a summary of the hypotheses and the supporting studies consecutively. Further discussion on the constructs and the theoretical justification for the research model can be read in a previous publication of this study [16]. 
Table 1. The constructs and definitions

\begin{tabular}{|c|c|}
\hline Construct & Definition \\
\hline Usage intention (UI) & $\begin{array}{l}\text { a measure of strength of individual's intention to use an SMS-based e- } \\
\text { government service [9]. }\end{array}$ \\
\hline Attitude towards use (A) & $\begin{array}{l}\text { The degree to which a person has a favourable or unfavourable evaluation of } \\
\text { using an SMS-based e-government service in question [8]. }\end{array}$ \\
\hline $\begin{array}{l}\text { Perceived behavioral } \\
\text { control (PBC) }\end{array}$ & $\begin{array}{l}\text { The extent to which a person perceives that the required opportunities and } \\
\text { resources to use an SMS-based e-government service are available for } \\
\text { him/her [8]. }\end{array}$ \\
\hline $\begin{array}{l}\text { Normative social } \\
\text { influence (NSI) }\end{array}$ & $\begin{array}{l}\text { A person's perception that most people who are important to him think he } \\
\text { should or should not perform the behaviour [8]. In the context of SMS-based } \\
\text { e-government, the survey revealed that individuals perceived normative social } \\
\text { influence (NSI) dominantly from family, friends or peers, and government [6]. }\end{array}$ \\
\hline $\begin{array}{l}\text { Perceived ease of use } \\
(\mathrm{PEU})\end{array}$ & $\begin{array}{l}\text { The degree to which a person perceives that using an SMS-based e- } \\
\text { government service is easy [9]. This perception covers usability on the } \\
\text { registration and unsubscribe methods, the text format for requesting } \\
\text { information, the service number (whether it is easy to remember or not), and } \\
\text { the way to use all of the service's functions [6]. }\end{array}$ \\
\hline $\begin{array}{l}\text { Perceived convenience } \\
\text { (PC) }\end{array}$ & $\begin{array}{l}\text { The degree to which a person believes that using an SMS-based e-government } \\
\text { service would give him/her flexibility and efficiency in time, place, effort and } \\
\text { control in accessing public services [6]. It represents perceived usefulness } \\
\text { construct in TAM relevant for SMS-based e-government services. }\end{array}$ \\
\hline Perceived risk (PRk) & $\begin{array}{l}\text { The degree to which a person believes that using an SMS-based e-government } \\
\text { service may cause problems for him/her. The concerns include risk of the } \\
\text { SMS technology, risk to user privacy and security, and perceived financial } \\
\text { risk [6]. }\end{array}$ \\
\hline $\begin{array}{l}\text { Perceived reliability and } \\
\text { quality of the } \\
\text { information (PRQI) }\end{array}$ & $\begin{array}{l}\text { The degree to which an individual perceives that the information delivered by } \\
\text { an SMS-based e-government is relevant for him/her, reliable and up-to-date } \\
\text { [6]. }\end{array}$ \\
\hline $\begin{array}{l}\text { Perceived personal } \\
\text { relationship (PPR) }\end{array}$ & $\begin{array}{l}\text { The degree to which an individual perceives that using an SMS-based e- } \\
\text { government service enables him/her to communicate directly and in-person } \\
\text { with the decision maker [6]. }\end{array}$ \\
\hline $\begin{array}{l}\text { Perceived } \\
\text { responsiveness (PRs) }\end{array}$ & $\begin{array}{l}\text { The degree to which individual perceives that an SMS-based e-government } \\
\text { service respond any incoming messages quickly and satisfactorily [6]. }\end{array}$ \\
\hline Perceived cost $(\mathrm{PCt})$ & $\begin{array}{l}\text { The degree to which a person perceives that an SMS-based e-government } \\
\text { service is costly. The perception covers individual consideration whether the } \\
\text { service charges users more than a standard SMS rate [6], comparison between } \\
\text { the SMS cost to other communication channels such as phone call or Internet } \\
\text { cost [8], and comparison between the cost and benefits they might obtain from } \\
\text { using the service }[11,17] \text {. }\end{array}$ \\
\hline $\begin{array}{l}\text { Perceived compatibility } \\
\text { (PCy) }\end{array}$ & $\begin{array}{l}\text { The degree to which individual perceives that an SMS-based e-government } \\
\text { service is consistent with the way the one communicates, the existing public } \\
\text { service channels and the popular communication media, and perceives the } \\
\text { service or the information contents is suitable being delivered by SMS }[6,23] \text {. }\end{array}$ \\
\hline $\begin{array}{l}\text { Facilitating conditions } \\
\text { (FC) }\end{array}$ & $\begin{array}{l}\text { Individual's belief on the availability of resources needed to use an SMS- } \\
\text { based e-government service, such as a mobile phone and phone credit }[6,10] \text {. }\end{array}$ \\
\hline Self-efficacy (SE) & $\begin{array}{l}\text { Individual's self-confidence in his/her capability to use an SMS-based e- } \\
\text { government service, including self-confidence in capabilities to use SMS, to } \\
\text { register to and unsubscribe from an SMS-based service, and to utilize an } \\
\text { SMS-based service's functions }[6,7] \text {. }\end{array}$ \\
\hline
\end{tabular}


Table 2. The research hypotheses and the supporting studies

\begin{tabular}{|c|c|c|}
\hline Hypot & Supporting s & \\
\hline Usage & ention constructs & \\
\hline H1 & $\mathrm{A} \rightarrow \mathrm{UI}$ & {$[7,9,12,17,19]$} \\
\hline $\mathrm{H} 2$ & $\mathrm{PBC} \rightarrow \mathrm{UI}$ & {$[7,12,19]$} \\
\hline $\mathrm{H} 3$ & $\mathrm{NSI} \rightarrow \mathrm{UI}$ & {$[7,12,19]$} \\
\hline Attituc & ial and control beliefs & \\
\hline H1.1 & $\mathrm{PEU} \rightarrow \mathrm{A}$ & {$[6,7,9,12,14,17,19,20]$} \\
\hline H1.2 & $\mathrm{PC} \rightarrow \mathrm{A}$ & {$[6,7,9,12,14,17,19,20]$} \\
\hline H1.3 & PRk $\rightarrow$ A (negative relationship) & {$[6,12]$} \\
\hline H1.4 & PRQI $\rightarrow$ A & {$[6,17,21]$} \\
\hline H1.5 & $\mathrm{PPR} \rightarrow \mathrm{A}$ & {$[6,14,22]$} \\
\hline H1.6 & PRs $\rightarrow$ A & {$[6,14]$} \\
\hline $\mathrm{H} 1.7$ & $\mathrm{PCt} \rightarrow \mathrm{A}$ (negative relationship) & {$[6,11,17]$} \\
\hline H1.8 & $\mathrm{PCy} \rightarrow \mathrm{A}$ & {$[6,7,12,16,23,24]$} \\
\hline $\mathrm{H} 2.1$ & $\mathrm{FC} \rightarrow \mathrm{PBC}$ & {$[6,11,12]$} \\
\hline $\mathrm{H} 2.2$ & $\mathrm{SE} \rightarrow \mathrm{PBC}$ & {$[6,7,12]$} \\
\hline Crosso & r effects between underlying be & \\
\hline H1.2.1 & $\mathrm{PEU} \rightarrow \mathrm{PC}$ & {$[9,25,26]$} \\
\hline H2.2.1 & $\mathrm{SE} \rightarrow \mathrm{PEU}$ & {$[25,27]$} \\
\hline
\end{tabular}

\section{Empirical Validation}

To perform an empirical validation of the model, this study conducted five main activities: developing measures for each variable of the model, data collection, assessing the validity and reliability of the measures, validating the model using the collected data, and modifying the model until the model-fitness parameters were satisfactory.

\subsection{Developing the Measures}

To ensure the validity of the measurements, this study initially generated the questionnaire by adopting related-question items validated in prior studies and modified them specifically to SMS-based e-government context. Items measuring usage intention were adopted from Turel et al.'s [11] and Venkatesh et al.'s [10] studies. Attitude, perceived behavioral control, and normative social influence scales were adopted from Ajzen's [8], Taylor and Todd's [7] and Nysveen et al.'s [19] studies. Items measuring the dimensions of attitude, perceived behavioral control and normative social influence were mainly adopted and generated from Davis et al.'s [9], Ajzen's [8], Taylor and Todd's [7] studies, and the survey findings on individuals' motivations for using or not using SMS-based e-government services [6]. Table 3 presents sources of the scales.

The questionnaire was available in two languages: English and Indonesian (Bahasa). The English questionnaire was translated in Bahasa then evaluated using back-translation method by bilingual reviewers. The questionnaire in Bahasa was also pretested on monolingual Bahasa-speaking respondents and modified based on the feedback. 
Table 3. Constructs and source of the scales

\begin{tabular}{|l|l|}
\multicolumn{1}{c|}{ Construct } & \multicolumn{1}{c|}{ Source of the scales } \\
\hline Usage intention (UI) & {$[10,11]$} \\
\hline Attitude toward using the services (A) & {$[7,8,19]$} \\
\hline Perceived ease of use (PEU) & {$[6,9,10,19,24,27]$} \\
\hline Perceived convenience (PC) & {$[6,19]$} \\
\hline Perceived reliability and quality of the information (PRQI) & {$[6,17,22,24]$} \\
\hline Perceived cost (PCt) & {$[6,11]$} \\
\hline Perceived personal relationship (PPR) & {$[6,14,22]$} \\
\hline Perceived compatibility (PCy) & {$[6,7,12,24]$} \\
\hline Perceived risk (PRk) & {$[6,12,24,25]$} \\
\hline Perceived responsiveness (PRs) & {$[6,14]$} \\
\hline Perceived behavioral control (PBC) & {$[7,8,19]$} \\
\hline Self-efficacy (SE) & {$[7,8,14]$} \\
\hline Facilitating conditions (FC) & {$[6,7,8,10,25]$} \\
\hline Normative social influence (NSI) & {$[6,7,8,10,12,19,24]$} \\
\hline
\end{tabular}

Initially, the measurement instrument was a questionnaire using a five-point Likert scale with anchors ranging from "strongly agree" to "strongly disagree". It contains 4 questions asking information about the used SMS applications, 4 questions about demographics, and 110 questions to measure the constructs of interest. To verify the questionnaire, a face validity test was conducted in turn.

Face validity refers to an assessment whether each question-item in the questionnaire seems like a reasonable/logical way to gain the information about the factor of interest, is well designed, clear and not ambiguous, concise, has adequate time limits, appropriate level of difficulty, appropriate patterns of the answers, and the instructions are clear. To conduct face-validity test, the questionnaire was reviewed by an expert in e-government, three statistics consultants, reviewers of the Behavior and IT journal, and pre-tested by 8 respondents (consisting English-speaking respondents as well as Bahasa-speaking respondents) who were asked to complete the questionnaire and to comment on any aspects of the questionnaire. Based on the feedback, the instruction and some questions were reworded slightly, some questions were worded with proper negation to reduce the potential monotonous responses (such as all answers are 'strongly agree' or 'strongly disagree'), and the redundant questions were eliminated. As result, the face validity test produced a modified questionnaire which used a sevenpoint Likert scale containing 4 questions about the SMS applications, 4 demographics questions and 59 questions to measure 14 constructs of interest.

\subsection{Samples}

Since the model focuses on factors that may influence non-adopters' intention to use SMS-based e-government services, this study validated the measures and the proposed model using data collected from individuals who have never used SMS-based egovernment even when the services are available for them. It involved citizens in three cities in Indonesia which have delivered SMS-based e-government services (i.e. Yogyakarta, Surabaya, and Solo). The respondents were told about available SMSbased e-government services in their cities and were encouraged to try the services before answering the survey. Data were collected using a paper-based survey. 
The participants were 589 citizens in three cities in Indonesia: 248 people $(42.1 \%)$ are residents of Surabaya, 191 people $(32.4 \%)$ are Solo's residents, and 150 people $(25.5 \%)$ are Yogyakarta's residents. With respect to the type of SMS-based e-government service, 121 respondents $(20.5 \%)$ evaluated Notification services, 235 (39.9\%) evaluated Pull services, 67 respondents $(11.4 \%)$ evaluated Listen services, 90 respondents $(15.3 \%)$ evaluated Transaction services, and 76 respondents (12.9\%) did not specify the service's type [1]. The majority of the respondents (522 people or $88.6 \%$ ) are students in a bachelor degree with the last completed education level the high school, 58 respondents $(9.8 \%)$ have completed a bachelor degree, 6 respondents $(1.0 \%)$ have completed master degree, 2 respondents $(0.3 \%)$ completed primary school, and one respondent $(0.2 \%)$ did not answer his/her education level. In terms of age and gender, the majority of the respondents are male (52.6\%), ages 18 up to 30 years old $(97.3 \%)$.

Before analysing the collected data, this study removed data from respondents who answered less than $75 \%$ of the questions as they were considered to not be serious or genuine in their answers. It was also checked for errors such as values that outside the range of possible values for a variable and the number of missing cases.

The collected data have relatively very small number of missing data that is $0.4 \%$. Since AMOS requires complete data to compute parameters of the model fit and modification indices, this study replaced missing data with the mean for the variable's data series based on the respondents' location [28]. For example, a missing datum of question UI1 (usage-intention1) of a respondent from Yogyakarta who evaluated an SMS-based e-government service in city of Yogyakarta was substituted with the mean for question UI1 of respondents from Yogyakarta.

\subsection{Measurement}

In addition to the face validity test, this study also ensured the construct validity and internal consistency-reliability of the measurement scale before assessing the models. Using SEM, AMOS 18, and data from the 589 samples, each construct (factor) with its items were modelled in conjunction with every other construct and the items in the model. It added curved arrows representing covariance between every pair of latent variables and left in the straight arrows from each latent variable to its indicator variables as well as left in the straight arrows from error and disturbance terms to their respective variables [28]. This study dropped items which have multiple regression weights $\left(r^{2}\right)$ less than 0.20 and there than remained 52 items all statistically significant ( $\mathrm{p}$ value $<0.01$ ) indicating convergent validity has been achieved [29]. The remaining items were assessed with respect to the discriminant validity using the correlation method [28, 30]. Discriminant validity was achieved since there was not a single item correlating more highly with a construct different from the one intended and all correlations between pairs of factors are less than 1.00. Moreover, the values of Conbrach's alpha for all constructs are between $0.616-0.865$ indicating the scales provided a reliable and consistent measure of the intended dimensions [31, 32 pp.675].

Next, in order to determine which model best explains intention to use SMS-based egovernment services, this study conducted alternative models (AM) and model generating $(\mathrm{MG})$ strategies. Initially, it compared four prominent technology adoption models (i.e. TRA, TAM, TPB, and DTPB) followed by validating the research model and generating a better-fit model. For each model, overall fit, predictive power $\left(\mathrm{R}^{2}\right)$ and the significance of the paths were considered, presented in Figures 2 and 3 and Tables 4. 


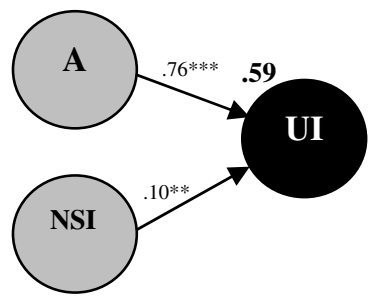

(a) The Theory of Reasoned Action

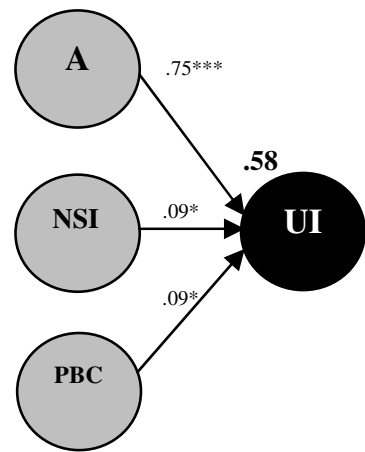

(c) The Theory of Planned Behavior

*** denotes significance at the $\mathrm{p}<0.001$ level

$* *$ denotes significance at the $\mathrm{p}<0.01$ level

$*$ denotes significance at the $\mathrm{p}<0.05$ level

$\ldots$ denotes not significant

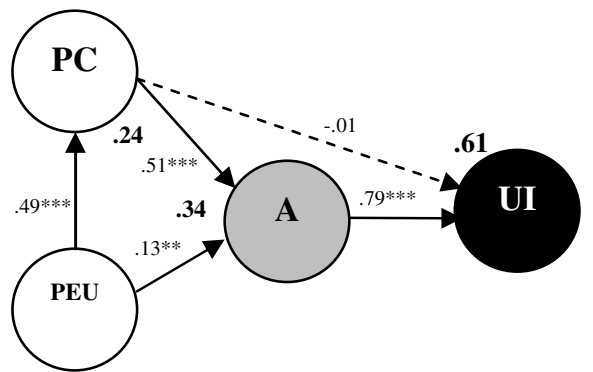

(b) The Technology Acceptance Model

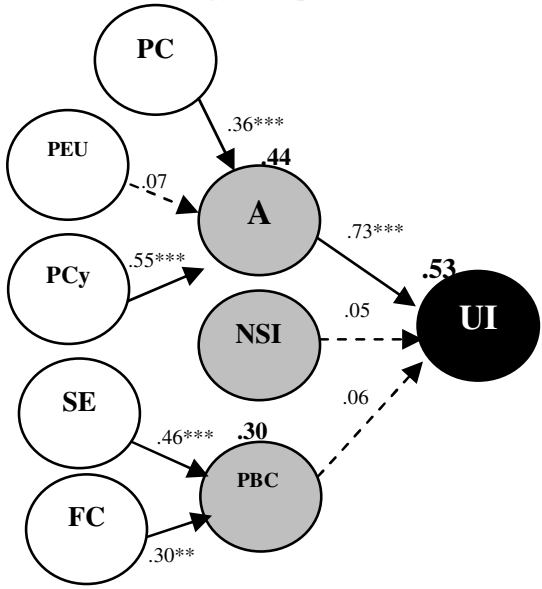

(d) The Decomposed Theory of Planned Behavior

Fig. 2. SEM of TRA, TAM, TPB, and DTPB

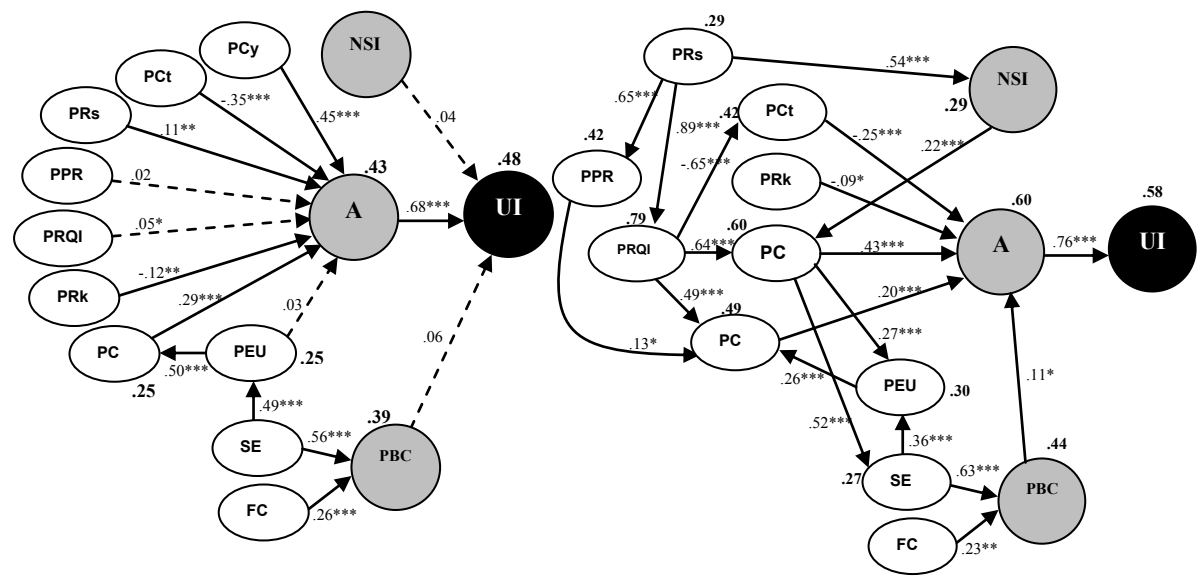

Fig. 3. The research model (left) and the final model (right) 
Table 4. Fit statistics and explanatory power of TRA, TAM, TPB, DTPB, the research model and the final model $[30,33]$

\begin{tabular}{|c|c|c|c|c|c|c|c|}
\hline Parameters & Recommended & TRA & TAM & TPB & DTPB & $\begin{array}{c}\text { Research } \\
\text { Model }\end{array}$ & $\begin{array}{l}\text { Final } \\
\text { model }\end{array}$ \\
\hline$\lambda^{2}$ & The lower the better & 217.642 & 286.545 & 363.870 & 1757.358 & 3648.895 & 2540.039 \\
\hline$\lambda^{2} / \mathrm{df}$ & $<2$ or $<5$ & 4.267 & 2.581 & 3.639 & 3.207 & 2.907 & 2.035 \\
\hline RMSEA & $<0.05$ or $<0.08$ & 0.075 & 0.052 & 0.067 & 0.061 & 0.057 & 0.042 \\
\hline IFI & $\geq 0.95$ or $>0.90$ & 0.950 & 0.967 & 0.928 & 0.865 & 0.826 & 0.906 \\
\hline TLI & $\geq 0.95$ or $>0.90$ & 0.935 & 0.959 & 0.913 & 0.852 & 0.816 & 0.900 \\
\hline CFI & $\geq 0.95$ or $>0.90$ & 0.949 & 0.967 & 0.927 & 0.864 & 0.826 & 0.906 \\
\hline PRATIO & The closer to 1.0 the better & 0.773 & 0.816 & 0.833 & 0.921 & 0.946 & 0.941 \\
\hline $\mathrm{R}_{\mathrm{ui}}^{2}$ & The higher the better & $59 \%$ & $61 \%$ & $58 \%$ & $53 \%$ & $48 \%$ & $58 \%$ \\
\hline
\end{tabular}

\subsection{Results and Discussion}

Overall, the fit statistics indicate that TRA, TAM, and TPB models provide good fit to the data, while DTPB slightly below of the recommended criteria. The TAM model accounts for $61 \%$ of the variance in usage intention, the highest explanatory power of the other three prominent models. The TPB model provides a good fit to the data and explain usage intention lower than TAM. The addition of social normative influence does not, in this case, help to better understand usage intention relative to TRA and TAM. The DTPB and the research model (which is also an extension of the DTPB model) provide a bit lower fit-indices to the data in terms of IFI, TLI and CFI, but a good fit in terms of $\lambda^{2} / \mathrm{df}$, RMSEA, and PRATIO indices. Thus, the research model was modified and re-estimated based on modification indices and theoretical basis. Figure 3 (the right image) presents the final model, which is called SMS-based EGovernment Acceptance Model (SEGAM).

In addition to the original constructs of the DTPB model, the SEGAM introduced six beliefs specifically for SMS-based e-government services: perceived convenience (representing perceived usefulness of SMS-based e-government), perceived risk, perceived reliability and quality of the information, perceived personal relationship, perceived responsiveness, and perceived cost. Nine hypotheses of the research model were accepted (H1, H1.2, H1.3, H1.7, H1.8, H2.1, H2.2, H2.2.1, H1.2.1), while the other six hypotheses were rejected (H2, H3, H1.1, H1.4, H1.5, H1.6). The SEGAM can explain $58 \%$ of the variance in usage intention with all paths significant, which is better than the original DTPB model and comparable with the TPB model. The introduction of the six attitudinal beliefs, even does not provide a better prediction of usage intention relative to TPB, provides a better prediction of attitude relative to pure DTPB and TAM $\left(\mathrm{R}_{\mathrm{A}}^{2}=60 \%\right.$, relative to $\mathrm{R}_{\mathrm{A}}^{2}=44 \%$ for DTPB and $\mathrm{R}_{\mathrm{A}}{ }_{\mathrm{A}}=34 \%$ for TAM).

All of the examined models suggest that individual's attitude towards using an SMS-based e-government service plays a central role in influencing intention to use the service. The SEGAM suggests that the other beliefs influence intention indirectly through attitude and the attitudinal beliefs. The explanation for such a finding is based on the fact that SMS-based e-government services are present in daily live setting and fully voluntary, so intention to use the services will be formed based simply on personal likes or dislikes with respect to utilizing the services rather than due to social pressure. Moreover, by currently high penetration of SMS and mobile phone, availability of the mobile network in most places, simplicity of the SMS technology and low SMS cost, perceived behavioral control on using an SMS-based service may 
not be a problem for most citizens. To promote an acceptable SMS-based egovernment service, government should develop citizens' positive attitude towards using the service.

In order to improve a positive attitude towards using an SMS-based e-government service, the SEGAM suggests government and the system designers to pay attention more on the compatibility of the service with other public services and common communication channels, to provide free SMS-based service or the cost should not be more expensive than standard SMS rates, the service should provide more convenient access to public services, to promote a safe SMS-based channel, and to improve perceived behavioral control (such as to ensure reliability and availability of the SMSbased service 24/7). When a person perceives that an SMS-based e-government service is compatible with the way they communicate, they may perceive the service is easy to use and their self-efficacy to use the service may also increase. Social influence may influence attitude through perception on compatibility of the service. Perception about quality and reliability of the information may influence perceptions about the service cost, compatibility and benefits of the service. When an SMS-based e-government service provides a fast and satisfactory response any time users request the service, it may improve the users' perception on quality and reliability of the information, users may have a feeling to communicate more in-person with the government rather than with a machine, and a social pressure for using the service is likely present. People may feel more convenient to access a public service when they perceived they communicate in-person with government. Finally, individuals' perceptions of their self-efficacy to use the service and availability of the resources (such as mobile phone or phone credit) may improve their perceived behavioral control, which leads to a more favorable attitude towards using the services.

The proposed model, which includes details of attitudinal beliefs, control beliefs, and social beliefs (i.e. the measures include normative social influences from government, friends/colleagues/peers, family, respected people, and people around), provides a fuller explanation of usage intention of SMS-based e-government services and better predictive power of attitude, perceived behavioral control, and normative social influence $\left(\mathrm{R}_{\mathrm{A}}^{2}=60 \%, \mathrm{R}_{\mathrm{PBC}}^{2}=44 \%, \mathrm{R}_{\mathrm{NSI}}^{2}=29 \%\right)$ relative to the other models. This study argues that decomposing attitude, perceived behavioral control, and social norms into more specific beliefs can give more practical benefits [7]. It provides beliefs specifically relevant for the SMS-based e-government context that may be manipulated through systems design and implementation strategies.

\section{Conclusions}

This study compared four prominent models and proposed a model of user acceptance of SMS-based e-government services. It proposed 13 beliefs that may influence individuals to use or to reject SMS-based e-government services. Among the factors, attitude towards use is the strongest predictor of intention to use SMS-based egovernment services and perceived compatibility is the strongest predictor of the attitude towards use. In order to have acceptable SMS-based e-government services, government should accommodate all of the factors when developing and delivering the services. Government particularly should pay attention more on how to develop a 
positive attitude of citizens towards using the services through perceived compatibility of the services. The proposed model may enable governments to predict user acceptance of a new SMS-based e-government service and to evaluate existing services.

\section{References}

1. Susanto, T.D., Goodwin, R., Calder, P.: A Six-Level Model of SMS-based eGovernment. In: International Conference on E-Government 2008. ICEG, Melbourne (2008)

2. Lallana, E.C.: SMS, business and Government in the Philippines. In: ICT4D.ph (2004)

3. Bremer, A.A., Prado, L.A.L.: Municipal m-Services using SMS. In: Euro mGov 2006 (2006)

4. Alampay, E.A.: Text 2920/117: Reporting Police Wrongdoing via SMS in the Philippines in mGovernment Case Study. In: Heeks, R. (ed.) eGovernment for Development (2003)

5. Westlund, O.: Towards an understanding of the adoption and use of mobile Internet news, Roskilde Universitetscenter (2008)

6. Susanto, T.D., Goodwin, R.: Factors Influencing Citizen Adoption of SMS-based eGovernment Services. Electronic Journal of E-Government (2010)

7. Taylor, S., Todd, P.A.: Understanding Information Technology Usage: A Test of Competing Models. Information Systems Research 6(2), 144-176 (1995)

8. Ajzen, I.: The Theory of Planned Behavior: Organizational Behavior and Human Decision Processes. 50(2), 179-211 (1991)

9. Davis, F.D., Bagozzi, R.P., Warshaw, P.W.: User Acceptance of Computer Technology: A Comparison of Two Theoritical Models. Management Science 35(8), 982 (1989)

10. Venkatesh, V., et al.: User Acceptance of Information Technology: Toward a Unified View. MIS Quarterly 27(3), 425-478 (2003)

11. Turel, O., Serenko, A., Bontis, N.: User acceptance of wireless short messaging services: Deconstructing perceived value. ScienceDirect 44, 63-73 (2007)

12. Hung, S.-Y., Chang, C.-M., Yu, T.-J.: Determinants of User Acceptance of the eGovernment Services: The case of online tax filling and payment system. Government Information Quarterly 23, 97-122 (2006)

13. Yulong, K., Wenli, L.: A Study of the Factors Affecting the Adoption of Mobile Instant Messaging in China. In: Eighth International Conference on Mobile Business, Dalian, Liaoning, China (2009)

14. Dennis, A.R., Venkatesh, V., Ramesh, V.: Adoption of Collaboration: Integrating Technology Acceptance and Collaboration Technology Research, Sprouts (2003)

15. Mathieson, K.: Predicting User Intentions: Comparing the Technology Acceptance Model with the Theory of Planned Behaviour. Information Systems Research 2, 173-191 (1991)

16. Susanto, T.D., Goodwin, R.: User Acceptance of SMS Applications for Public Services. In: SESINDO, Surabaya, Indonesia (2010)

17. Scharl, A., Dickinger, A., Murphy, J.: Diffusion and Success Factors of Mobile Marketing. Electronic Commerce Research and Applications 4, 159-173 (2005)

18. Susanto, T.D., Goodwin, R.: Adoption Success Factors of SMS-based eGovernment: A Case Study of SMS-OBM and SMS-MIIAS. In: ICCIO, Bandung, Indonesia (2010)

19. Nysveen, H., Pedersen, P.E., Thorbjornsen, H.: Intentions to Use Mobile Services: Antecedents and Cross-Service Comparisons. Journal of the Academy of Marketing Science 33(3), 330-346 (2005) 
20. Aripin, N., Omar, S.Z.: Perception and Attitude of Short Messaging Services (SMS) Among Students of Universiti Utara Malaysia. In: Konferen Antarabangsa, Universiti Kebangsaan Malaysia, Bangi, Selangor (2007)

21. Almahamid, S., et al.: The relationship between perceived usefulness, perceived ease of use, perceived information quality, and intention to use e-government. Journal of Theoretical and Applied Information Technology, 30-44 (2010)

22. Barkhuus, L.: Why Everyone Loves to Text Message: Social Management with SMS. In: GROUP 2005. ACM, Sanibel Island (2005)

23. Rogers, E.M.: Diffusion of Innovations, 5th edn. Free Press, New York (2003)

24. Carter, L., Belanger, F.: The utilization of e-government services. Information Systems Journal 15, 5-25 (2005)

25. Wang, Y.-S., Lin, H.-H., Luarn, P.: Predicting consumer intention to use mobile service. Info. System 16, 157-179 (2006)

26. Ramayah, T., et al.: Predicting Short Message Service (SMS) Usage among university students using the Technology Acceptance Model (TAM). In: IAMOT 2006, Malaysia (2006)

27. Gong, M., Yan, X.: Applying Technology Acceptance Model, Theory of Planned Behavior and Social Cognitive Theory to Mobile Data Communications Service Acceptance. In: PACIS (2004)

28. Garson, G.D.: Statnotes: Topics in Multivariate Analysis (January 10, 2010), http://faculty.chass.ncsu.edu/garson/PA765/statnote.htm (cited October 29, 2010)

29. Hooper, D., Coughlan, J., Mullen, M.R.: Structural Equation Modelling: Guidelines for Determining Model Fit. The Electronic Journal of Business Research Methods 6(1), 53-60 (2008)

30. Bryne, B.M.: Structural Equation Modeling with AMOS., 2nd edn. Taylor \& Francis Group, New York (2010)

31. Hair, J.F., et al.: Multivariate data analysis, 5th edn. Prentice-Hall, New Jersey (1998)

32. Field, A.: Discovering Statistics Using SPSS, 3rd edn. SAGE Publication Ltd., London (2009)

33. Hu, L.T., Bentler, P.M.: Cutoff criteria for fit indexes in covariance structure analysis: Conventional criteria versus new alternatives. Structural Equation Modeling 6 (1999) 